\title{
A smoking cessation programme plus inhaled ipratropium improved survival in asymptomatic airway obstruction
}

Anthonisen NR, Skeans MA, Wise RA, et al. The effects of a smoking cessation intervention on 14.5-year mortality: a randomized clinical trial. Ann Intern Med 2005;142:233-9.

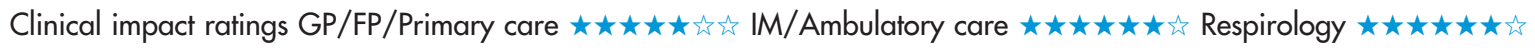

In current smokers with asymptomatic airway obstruction, is a smoking cessation programme (SCP) with or without inhaled ipratropium more effective than usual care (UC) for reducing all cause mortality?

\section{METHODS}

$\square$

Design: randomised placebo controlled trial (Lung Health Study [LHS]

2

Allocation: unclear allocation concealment.*

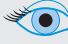

Blinding: unblinded.*

$\sum\langle$

Follow up period: 14.5 years.

Setting: 10 clinical centres in the US and Canada

으 Participants: 5887 smokers 35-60 years of age (mean age 48 $y, 63 \% \mathrm{men}$ ) who had asymptomatic airway obstruction.

R

Intervention: a 10 week SCP that included a strong physician message and 12 two hour group sessions using behaviour modification and nicotine gum, plus either inhaled ipratropium $(n=1961)$ or a placebo inhaler $(n=1962)$. A third group received UC $(n=1964)$.

1 Outcomes: all cause mortality.

象

Patient follow up: 100\% (intention to treat analyses).

${ }^{*}$ See glossary.

\section{MAIN RESULTS}

At 5 years, more patients in the intervention group (with or without ipratropium) than in the UC group had stopped smoking $(21.7 \% \mathrm{v}$ $5.4 \%, \mathrm{p}<0.05)$. At 14.5 years, $12.4 \%$ of patients had died. Compared with UC, the rate of all cause mortality was lower in patients receiving SCP plus ipratropium or placebo, and in patients receiving .......................................................... MN, USA. john-c@ccbr.umn.edu

Source of funding: National Heart, Lung, and Blood Institute.
SCP plus ipratropium (table). The SCP plus placebo and UC groups did not differ, and the SCP plus ipratropium and SCP plus placebo groups did not differ for all cause mortality (table).

\section{CONCLUSION}

In current smokers with asymptomatic airway obstruction, a smoking cessation programme plus inhaled ipratropium was more effective than usual care for reducing all cause mortality.

\section{Abstract and commentary also appear in ACP Journal Club.}

\section{Commentory}

7 he study by Anthonisen et al is the first to show a significant long term mortality benefit among patients who have participated in an SCP.

The benefit was relatively small, with an absolute risk reduction of about $2 \%$ after 14.5 years. However, this is the benefit for all patients randomised to the SCP, not just those who quit smoking. Furthermore, $21.7 \%$ of patients in the SCP had quit smoking after 5 years compared with $5.4 \%$ in the UC group. When the deaths were analysed by smoking status, those who quit had a mortality rate of 6 per 1000 person years, compared with 11 per 1000 person years in those who continued to smoke. These findings are similar to other cohort studies of smoking cessation, ${ }^{1}$ and presumably represent a more accurate reflection of the benefit for those who quit.

The programme itself was intensive, including 12 two hour sessions over 10 weeks in patients with asymptomatic airway obstruction and little evidence of other disease. Whether the benefit would be the same in other patient populations is not known. The meta-analysis in the 2000 Public Health Service Clinical Practice Guideline noted no increase in cessation rates for interventions that included $>8$ sessions or 30 minutes of total contact time. The quit rates in these groups were $24.7 \%$ and $26.5 \%$, respectively, ${ }^{2}$ similar to the $21.7 \%$ cessation rate in the study by Anthonisen et al. These data form the basis for the new Medicare coverage benefit for up to 8 smoking cessation sessions per year. This study provides evidence that such interventions can significantly improve survival and therefore should be routinely available to all patients who smoke.

John B Schorling, MD, MPH University of Virginia School of Medicine Charlottesville, Virginia, USA

1 US Department of Health and Human services. Smoking cessation and cardiovascular disease: A report of the Surgeon General. 1990;201-25. http://profiles.nlm.nih.gov/NN/B/B/C/T/ (accessed 10 Aug 2005)

2 US Department of Health and Human Services. Clinical Practice Guideline. Treating tobacco use and dependence. Public Health Service June 2000. http://www.surgeongeneral.gov/tobacco/clinpack.html (accessed 10 Aug 2005)

A smoking cessation programme (SCP) plus inhaled ipratropium or inhaler placebo $v$ usual care (UC) in current smokers with asymptomatic airway obstruction at 14.5 years*

\begin{tabular}{|c|c|c|c|c|}
\hline Outcome & Comparisons & Event rates & $\operatorname{RRR}(95 \% \mathrm{Cl})$ & NNT (Cl) \\
\hline $\begin{array}{l}\text { All cause } \\
\text { mortality }\end{array}$ & $\begin{array}{l}\text { SCP (with or without iprotropium) } v \text { UC } \\
\text { SCP plus ipratropium } v \text { UC } \\
\text { SCP plus placebo } v \text { UC } \\
\text { SCP plus ipratropium } v \text { SCP plus placebo }\end{array}$ & $\begin{array}{l}11.8 \% \vee 13.7 \% \\
11.5 \% \vee 13.7 \% \\
12.0 \% \vee 13.7 \% \\
11.5 \% \vee 12.0 \%\end{array}$ & $\begin{array}{l}14.5 \%(1.6 \text { to } 25.7) \\
16.2 \%(1.1 \text { to } 28.9) \\
12.9 \%(-2.6 \text { to } 26.0) \\
3.8 \%(-14.2 \text { to } 18.9)\end{array}$ & $\begin{array}{l}51 \text { (26 to } 487) \\
45 \text { (24 to 695) } \\
\text { Not significant } \\
\text { Not significant }\end{array}$ \\
\hline
\end{tabular}

*Abbreviations defined in glossary; RRR, NNT, and $\mathrm{Cl}$ calculated from data in article. 